\title{
An Agent Based Model to Estimate Lynx Dispersal if Re-Introduced to Scotland
}

\section{Ian Philips ${ }^{1}[$ (]}

Received: 20 December 2017 / Accepted: 19 March 2019/

Published online: 23 April 2019

(C) The Author(s) 2019

\begin{abstract}
Re-introduction of Eurasian Lynx to Scotland is being considered. Work by others has provided an ecological rationale for reintroduction and trial re-introductions are proposed on the Scottish border. This paper presents an Agent Based Model which simulates the potential for individual lynx to successfully disperse from a release point, using movement rules derived from observation of wild lynx in Europe. Results suggest high mortality from road crossings could hinder effective dispersal. The model is used to suggest the strongest candidate release site based on dispersal with and without a road mortality effect. This occurs in the Galloway Forest Park. The model is built using open source tool Netlogo, the programming language is relatively straightforward and extensible so other life events and human interactions can be modelled. Movement parameters can easily be reset to explore other hypothesised movement patterns. This paper contributes to spatio-temporal understanding of lynx dispersal, via a dynamic visual representation of movement in an ABM. This may help appraise the case for re-introduction in a particular location as well as providing a discursive tool that may help to understand and resolve concerns of community stakeholders, which would aid development of suitable policies. Model code is available via online repository: https://github.com/DrIanPhilips/LynxABM.
\end{abstract}

Keywords Agent based model $\cdot$ Eurasian Lynx $\cdot$ Scotland $\cdot$ Rewilding

\section{Introduction}

There are philosophical and scientific arguments for reintroduction of predators such as the Eurasian Lynx (Lynx lynx) to Scotland (Brown et al. 2011). The Lynx UK Trust (Lynx UK Trust, Clifford Chance, and University of Cumbria 2017) applied for a trial re-introduction of Lynx in Kielder Forest on the Scottish border in 2017. They

Ian Philips

i.philips@leeds.ac.uk

1 Institute for Transport Studies University of Leeds, Leeds LS29JT, UK 
proposed a trial release over a period of five years with six GPS collared lynx being released. The proposal was rejected by the UK Government. Several reasons for rejection were given including lack of detail in ecological assessment (DEFRA 2018). Where there is an active political debate over species re-introduction the need for scientific evidence is highlighted by Arts et al. (2012). Spatial analysis forms a suitable component of that evidence base including for example landscape classification as well as simulation (e.g. Carver et al. 2012; Holt et al. 2018; Grimm and Railsback 2005).

The conservation and ecological arguments in favour of reintroduction of the Lynx to Scotland can be summarised as follows. Ecological theories of keystone species (e.g. Mills et al. 1993) state fully functional ecosystems need the regulatory mechanism of top predators. For example, natural vegetation regeneration may be aided by a predator ensuring ungulates (roe deer are the prey of choice for lynx) move and do not exert excessive grazing pressure on regenerating areas (Dennis 1995). Reintroduction acts to protect against global extinction (Kramer-Schadt et al. 2005). Lynx is a species extirpated from Scotland in historical times likely in the period 600-900 AD, due to a combination of deforestation, reduction in prey availability and persecution by humans (Hetherington 2005). Sufficient habitat exists for re-introduction in the Grampians and the Southern Uplands in terms of morphology, vegetation cover prey density and viable corridors between core areas of potential habitat (Hetherington 2005) using cost path analysis. Cost path analysis is a raster GIS processing technique; each cell has a 'cost' value to traverse it. Hetherington calculated cost paths as the sum of all raster cell values which must be crossed to get between core areas of potential habitat. However, with this approach there is a lack of information about movement dynamics over time which may provide further information in the ecological appraisal of re-introduction.

The lack of understanding of movement dynamics relate to continuing social and political issues: Farmers lobbies may be opposed to lynx re-introductions (Wyver 2014) through concerns that lynx would visit farmland and attack game and livestock, though Hetherington (2006) argues predation rates would be low. The re-introduction process is said to have left farmers disenfranchised with the process - there have been illegal killings of lynx following reintroductions in Switzerland. (Hetherington 2006; Devineau et al. 2010). Wildlife collisions with road traffic may hinder re-introduction viability and cause a traffic safety hazard (Gunson et al. 2011). Without acceptance by stakeholders successful reintroduction is less likely. Brown et al. (2011) discuss the possibility of rewilding in Scotland and recommend reintroduction should be carried out through stakeholder partnership, Milner and Irvine (2015) also advocate education and building relationships with stakeholders.

The discussion above identifies two needs, firstly for simulation of movement patterns in the absence of Scottish observation data to contribute to the ecological appraisal of lynx re-introduction and secondly there is a need to provide discursive tools to help stakeholders develop suitable policies. This paper proposes an Agent Based Model (ABM) - a computer simulation which models the actions and interactions of individuals and or their environment (Railsback and Grimm 2011; Bonabeau 2002). The proposed ABM is a flexible tool which considers how a released population of individual lynx 'agents' might disperse and colonise areas of habitat which provide sufficient prey 
during the dispersal period, and, which may later be suitable for establishing territories. This is useful because considering individual lynx movement provides information to help appraise the likely viability of conservation initiatives (Zimmermann and Breitenmoser 2007; Zimmermann et al. 2005). ABM has been used as a participatory modelling tool (e.g. Prell et al. 2007; Hare et al. 2003). The model presented in this paper is not a fully developed participatory tool, however there is some potential to develop it further in this area in the future using the principles outlined in Ramanath and Gilbert (2004). This may be provide a means to address some stakeholder concerns.

\section{Methodology - Agent Based Modelling}

The movement of lynx needs to be simulated because wild lynx are currently not present in the UK. If a controlled trial release such as it is being proposed by the Lynx UK Trust goes ahead, then models which can input empirical movement data from the trial would be useful in informing discussions of wider re-introduction. Gaining information about potential effects reduces risk of negative outcomes for the lynx themselves, the ecosystem and the human communities. This section considers different ways that lynx dispersal in Scotland could be modelled before offering a rationale for taking an ABM approach. Habitat assessment is a key pre-cursor for modelling dispersal. In Scotland, potential lynx habitat has been identified. Hetherington (2005) carried out raster GIS analysis of vegetation, land-use and other landscape features. Woodland is the preferred habitat of lynx but they can move across open ground between wooded areas within their territory.

Building on a habitat model, raster GIS cost path analysis (Hetherington 2005) and gravity models (e.g Bossenbroek et al. 2001) are examples of static means of representing potential lynx movement. The cost path model assumes all lynx will discover and take the least cost path in a deterministic manner. A gravity model provides an estimate of the relocation of animals between areas. It is also deterministic. Cost path analysis and gravity models do not allow for variation in lynx behaviour. Both give little idea of the probability of lynx exploring a particular area in a given period of time. Population Viability Analysis (e.g., Soule 1987) and differential equation based representations of population dynamics models may provide an aggregate estimate of the outcome of dispersal following release, but these models are not necessarily spatially explicit. Additionally the mathematical representation of these models is a barrier to use as a consultation tool with stakeholders (Wilensky and Rand 2015).

\section{Rationale for Using an Agent Based Model}

The arguments in favour of $\mathrm{ABM}$ are that they dynamically simulate the behaviours of individual agents, in this case lynx, and their interactions with the environment (Grimm and Railsback 2005; Bousquet and Le Page 2004; McLane et al. 2011). The complicated multi-parameter nature of ecological 
systems make ABMs well suited for modelling them (Grimm and Railsback 2005, Dunning et al. Dunning et al. 1995, Lima and Zollner 1996). ABM are suited to solve spatial problems where agents may need to act not just according to their attributes, but, also on the environment's spatial structure (O'Sullivan 2008), as in this case, where lynx agents have to disperse within a specific habitat (Kramer-Schadt et al. 2005). There have been a number of other successful applications of ABM to study animal movement (Tang and Bennett 2010) including some specific studies of big cats (e.g. Carter et al. 2015; Watkins et al. 2015).

Lynx agents can be programmed to behave using a small number of relatively simple stochastic rules such as how far to travel each day, whether to venture out of their preferred woodland habitat, and which direction to travel. The pattern of dispersal will be dependent upon the nature of the environment, the relative size and position of habitat areas, the location of barriers and the behaviour of the individual lynxes. A great deal of complexity can be incorporated simply which might be much more difficult in other modelling approaches. The emergent behaviour provides insight into the overall outcome; will lynx survive and will they explore sufficient territory in their dispersal phase? (Railsback and Grimm 2011; Wilensky and Rand 2015).

The scope of this paper is to describe an Agent Based Modelling (ABM) approach to simulate the potential for reintroduced Eurasian lynx to disperse from a release point in Scotland. Dispersal is the first step in determining population viability (Lima and Zollner 1996, Schippers et al 1996). It is beyond the scope of this model to be a complete spatial decision support system - the results of this study must be contextualised with other indicators and models and discussions with local stakeholders. ABM should also be used with the caveat that forecasting too far into the future (e.g. decades) creates excessive uncertainty (Wooldridge 2009), and changing model inputs and parameters can also cause great variation in results.

ABM typically produce visual output (in the present paper part of the output includes lynx moving about on a map of Scotland). Some ABM software, such as Netlogo ${ }^{1}$ used in the current paper, also features user controls such as sliders in a Graphical User Interface (GUI). This feature provides potential as a participatory tool or learning tool (Newman et al. n.d.; Wilensky and Rand 2015). This is valuable given that the debate on lynx re-introduction notes human acceptance as a key factor and adds to the relevance of the model (Milner and Irvine 2015; McLane et al. 2011).

\section{Model Description}

The model description follows the ODD (Overview, Design concepts, Details) protocol for describing individual- and agent-based models (Grimm et al. 2006, 2010).

\footnotetext{
$\overline{{ }^{1} \text { https://ccl.northwestern.edu/netlogo/ }}$
} 
Netlogo, a multi-agent programmable modelling environment, is used because simple language structure allows relatively rapid development of models, which can incorporate large numbers of 'patches' representing raster grid cells with dynamic properties as well as moving individual agents. Time and movement can be modelled and extensions allow input and output of GIS readable files (Wilensky and Reisman 2006). Netlogo procedures and parameters are easily adjusted. This has advantages when verifying and calibrating the model.

\section{Purpose}

The aim is to simulate lynx movement and dispersal in Scotland (and in Kielder Forest on the England / Scotland border). The approach is to implement the same movement rules developed for an ABM of lynx movement in Germany (Kramer-Schadt et al. 2004). The movement rules were derived from radio collar observation data collected in the Swiss Jura.

The questions asked of the model are: How would lynx disperse in Scotland if they were to follow the same movement rules, suffer the same mortality rates and are modelled with the same behavioural parameters as lynx in the Swiss Jura? Specifically. How far would Eurasian Lynx (Lynx lynx) disperse in their first year if re-introduced to Scotland? Would they explore enough suitable habitat to suggest that establishing territories is likely? How does the maximum distance a lynx is prepared to travel through sub-optimal matrix habitat affect the results?

\section{Entities, State Variables and Scales}

Patches Are square spatial units which represent the landscape of Scotland and areas close to the English border including Kielder Forest. Patches have a cell length of $1 \mathrm{~km}$. They are characterized by their type, whether they have been visited by a lynx and whether they contain a major road (UK ' $A$ ' road) or motorway.

The patches have a variable type which defines the suitability for lynx: The three types are "Dispersal patches" which are primarily wooded preferred habitat - coloured green in the map window of model GUI (See Fig. 1). These patches are the preferred habitat of lynx as they are ambush predators using the forest cover during hunting (Breitenmoser et al. 2000). "Matrix patches" areas into which lynx may venture but which were not preferred habitat - coloured yellow in the model interface. "Barrier patches" such as lochs and large urban areas - these were coloured red. Kramer-Schadt et al. (2004) also used these categories. However a subset of frequently used dispersal patches was labelled 'breeding habit' which was used in further models of lynx demographics (Kramer-Schadt et al. 2004).

In the present model, the landscape raster data, upon which the lynx agents move, was processed in ArcGIS derived principally from Scottish habitat data produced by Hetherington (2005). In addition, the Kielder Forest area along the Scottish border was estimated from the 2006 Corrine $250 \mathrm{~m}^{2}$ cell data. Core

\footnotetext{
$\overline{2}$ https://www.eea.europa.eu/data-and-maps/data/clc-2006-raster-4
} 


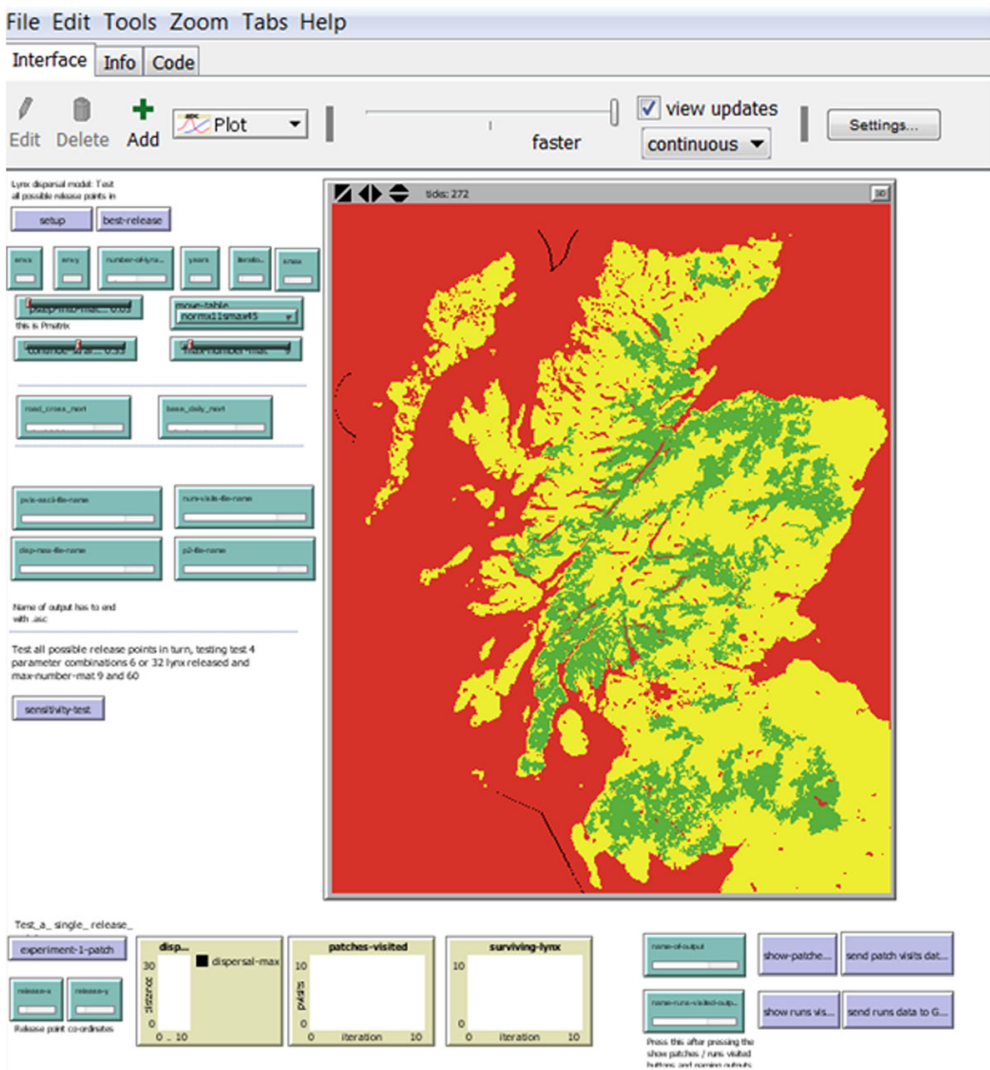

Fig. 1 The Netlogo user interface showing the lynx dispersal ABM, key parameters are easily changed allowing comparisons of simulations

habitat areas defined by Hetherington as a polygon Shapefile had the core habitat area of Kielder Forest appended to it. These were converted to a $1 \mathrm{~km} \times 1 \mathrm{~km}$ raster and classified as Dispersal habitat. Using the Corrine $2006250 \mathrm{~m}$ land classification cell data, cells defined as major urban areas or open water were reclassified as barrier. The reclassification of the Corrine raster was aggregated to a $1 \mathrm{kmx} 1 \mathrm{~km}$. Using the ArcGIS raster calculator, cells which were neither barrier nor dispersal habitat were then defined as matrix habitat. The patches have a further attribute hasroad indicating whether a major road or motorway is present in the patch. The roads dataset used (see Table 3) is downloaded in vector format. It is then cropped to the same extent as the patches data before being converted to a raster grid of the same extent and resolution as the patches data.

Lynx Are agents representing Eurasian lynx released from a release site, they are characterized by their location, their direction of travel and how far they will travel each day. If they are on a matrix patch rather than on dispersal patch, they remember the characteristic of the last dispersal patch they visited (Table 1). 


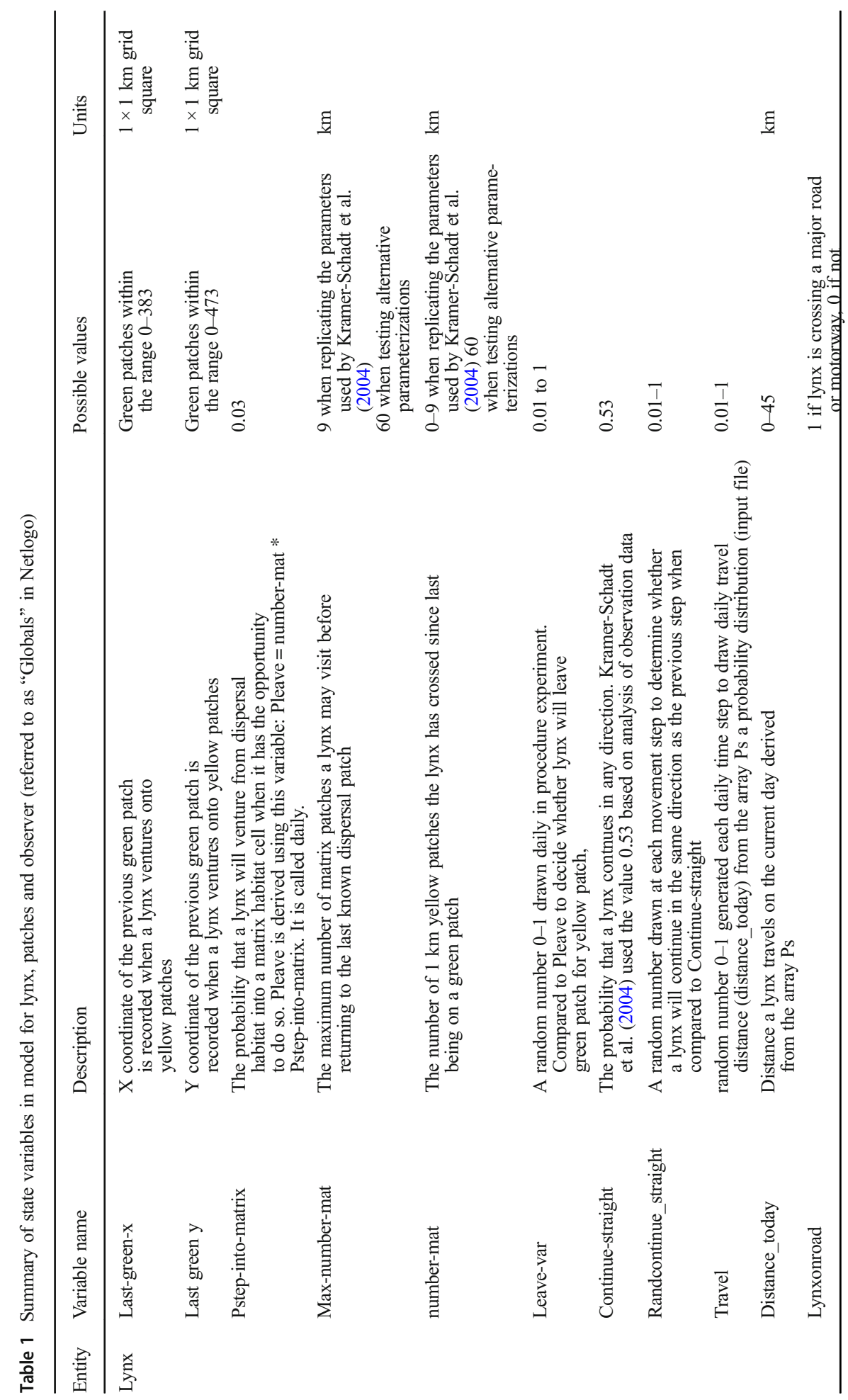




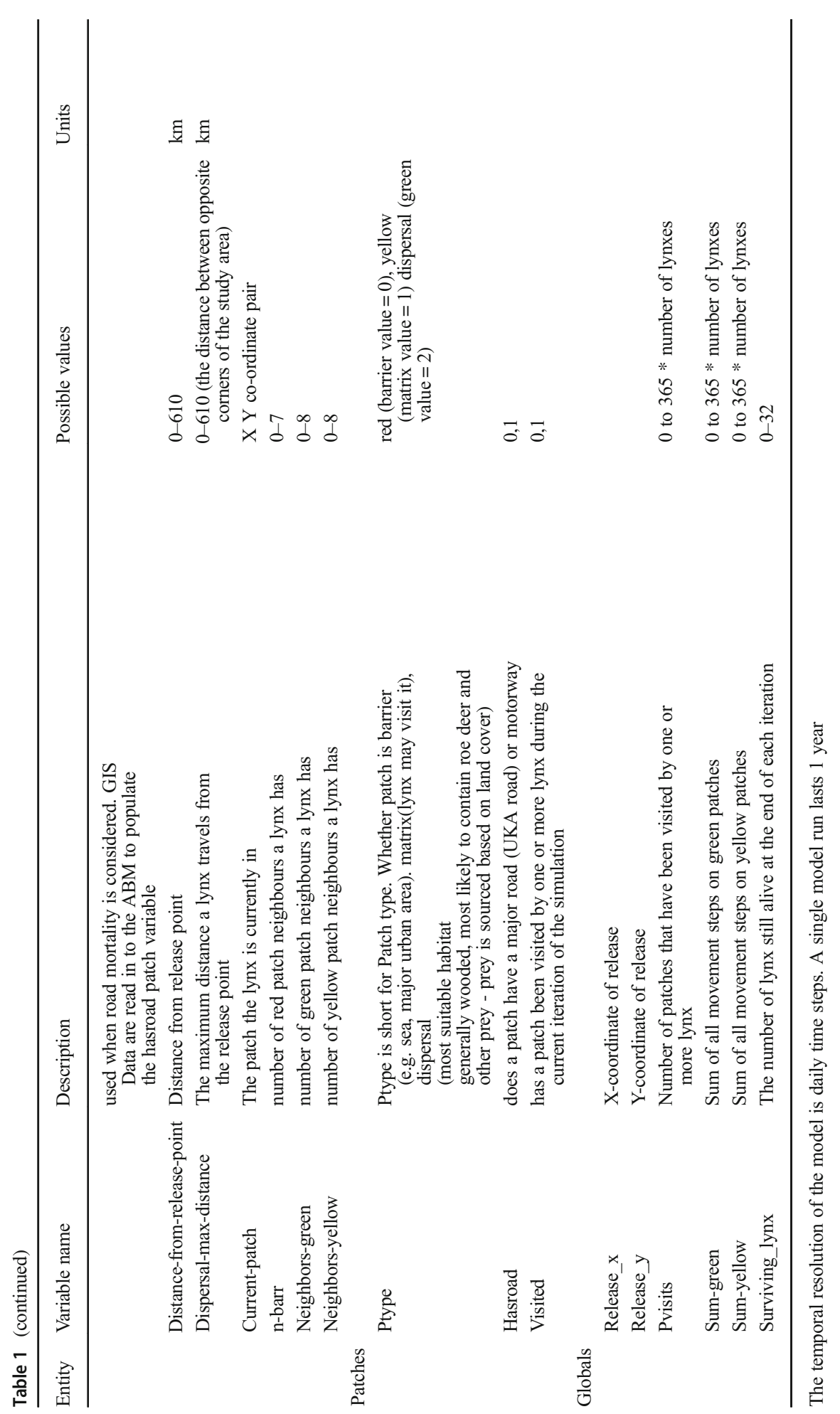




\section{Process Overview and Scheduling}

\section{Set_up}

The model first establishes which release points are to be tested. The model can be run at a single release point by typing in the co-ordinates to the GUI or it can be run in turn for all possible release points.

To Set_up_release_points_to_test

$$
\text { If [Test_a_single_release_point }=\text { TRUE, }
$$

Use coordinates typed into GUI

Simulate_release]

Else [

;:Test all possible release points in turn.

Repeat [all patch y values

Repeat [all patch $x$ values

If [patch colour $=$ Green $[; ;$ call these procedures

$$
\text { Set_up_Scotland }
$$

Set_up_lynxes

Run_simulation_experiment

To Set_up_Scotland

Load GIS data to patches

To Set_up_lynxes

Initialize the desired number of lynx

\section{Run Simulation Experiment}

The simulation experiment for a particular patch executes the following sub-models in each one day time step; Baseline_mortality, Movement, Road_crossing_mortality and 
Update_Globals. The pseudo-code below provides an overview of the process and their ordering. The order of processes is the same as that described in Kramer-Schadt et al. (2004).

\section{To Run_Simulation_experiment}

Set number of days per iteration (365)

Set number of iterations (50)

Repeat [iterations

Repeat [days per iteration

;;call these procedures

Baseline_mortality

Movement [if cross a major road $=$ TRUE, road_crossing_mortality]

Update_Globals

1

]

\section{Design Concepts}

Lynx movement rules during dispersal are based on the need to hunt, disperse and explore patches in the landscape which may later become a territory. The ABM models four interacting movement rules which are referred to as a Correlated Habitat Dependent Walk (CHDW) - movement direction is related to previous recent movement. Movement between different habitat types is also not random, but dependent on observed preferences. This replicates the principles of movement used in KramerSchadt et al. (2004). CHDW is a more sophisticated approach to modelling movement than a random walk (McLane et al. 2011). It considers the following;

1. Daily movement distance drawn from a probability distribution derived from observations. 
2. The likelihood of venturing from a dispersal patch into a matrix patch

3. Movement direction accounting for propensity to continue in a given direction

4. The maximum distance from its last dispersal patch that a lynx will venture into matrix patches.

\section{Emergence}

The shape and spatial extent of lynx dispersal emerges during simulation. The extent to which lynx move from one area of green dispersal patches to another emerges from the simulation. The emergent behaviour provides insight into the overall outcome; will lynx survive and will they explore sufficient territory in their dispersal phase (Railsback and Grimm 2011; Wilensky and Rand 2015).

\section{Adaptation}

Lynx movement responds to and adapts to the environment in the vicinity of each lynx through the CHDW.

\section{Objectives}

The success criteria is to identify locations where a released population of lynx generates at least $37 \mathrm{~km}^{2}$ of patch visits per released lynx. This is the average minimum territory area required per lynx.

\section{Learning}

If a lynx moves into matrix habitat, it remembers the location of the last dispersal habitat patch it visited so it can return there.

\section{Sensing}

Lynx are assumed to sense the patch type of the $1 \times 1 \mathrm{~km}$ habitat patch it standing on and the 8 neighboring patches. The patch types are based on land cover and level of prey availability.

\section{Interaction}

Individual lynx may occupy the same patch. Repulsion and attraction between individual lynx are not modelled explicitly as they are in some ABM (e.g. Carter et al. 2015). Lynx interact with the patches and their behaviours adapt to the environment as described above.

\section{Stochasticity}

The daily movement distance distance today, initial daily movement direction, and the decision to move into a matrix patch derived from Pstep_into_matrix are stochastic and are described above. The intra-day decision to continue moving in the same direction 
with each subsequent step, is also set stochastically by comparing a random number against the parameter continue_straight.

\section{Observation}

The following data are collected from each simulation to assess the objectives: Pvisits, the number of green dispersal habitat patches visited by one or more lynx in a simulation. This is done to assess the success criteria. Surviving_lynx is a count of the number of lynx still alive at the end of each iteration.

The following data are collected from each simulation to assess two pattern matching validation tests (Grimm and Railsback 2005; Kramer-Schadt et al. 2004If the model adheres to these patterns it gives evidence that the behaviour of the model is calibrated to observed data. Percent_matrix is the proportion of movement steps spent in matrix habitat derived from Sum-yellow and Sum-green. The observational data found the mean time spent in dispersal habitat was $81 \%$. In Kramer-Schadt et al's model, the calibration pattern was satisfied when the simulation produced more than $81 \%$ of lynx movement in dispersal patches. Dispersal-max-distance is the maximum distance from the release point of any lynx within one iteration was collected to assess a second pattern which was satisfied when the simulation produced a mean maximum distance which contained $41.7 \mathrm{~km}$ within 1 Standard deviation of the simulation mean maximum distance. This is the same test used by Kramer-Schadt et al. (2004).

\section{Initialization}

In the Set_up_Scotland procedure, two GIS rasters are read in. These are used to set the patch variables Ptype, and hasroad. A probability distribution is read in, which is used during simulation with the lynx variable travel to set the daily travel distance. Lynx are then initialized. The initial parameter values are shown in Table 2.

\section{Input Data}

Table 3 lists the data sets read into the model during the Set_up_Scotland procedure. The derivation of this data described above in Section 3.3.

\section{Sub-Models}

\section{Base Mortality}

The base mortality rate is the same as that used by Kramer-Schadt et al. (2004). It is calculated at the start of each day. The base mortality rate Base_daily_mort is listed in Table 1.

\section{Movement}

This sub-model was coded using details provided in (Kramer-Schadt et al. 2004). The modelling of movement based on Correlated Habitat Dependent Walk (CHDW) has several components. 
Table 2 Summary of default parameter information used in an agent based model of lynx dispersal in Scotland

\begin{tabular}{|c|c|c|}
\hline Variable & Initial variable value at $t=0$ & notes \\
\hline Move-table & $\begin{array}{l}\text { Probability distribution with a maximum } \\
\text { daily travel of } 45 \mathrm{~km} \text { with a distance } \\
\text { decay exponent of } 11\end{array}$ & \\
\hline Number_of_lynxes & 6 & \\
\hline Years & 1 & \\
\hline Smax & 45 & \\
\hline Pstep_into_matrix & 0.03 & \\
\hline Continue-straight & 0.53 & \\
\hline Max-number-mat & 9 & \\
\hline $\begin{array}{l}\text { Iterations (number } \\
\text { of model runs) }\end{array}$ & 50 & $\begin{array}{l}\text { This means results are from } 50 \text { runs of a set } \\
\text { of parameters. Results reported are the } \\
\text { average from } 50 \text { runs }\end{array}$ \\
\hline Release $\mathrm{x}$ & $0-383$ & When every patch is tested in sequence \\
\hline Release y & $0-473$ & When every patch is tested in sequence \\
\hline Base_daily_mort & $7.0 \mathrm{E}-4$ & \\
\hline Road_cross_mort & 0.002 & \\
\hline
\end{tabular}

Set Number of Movement Steps Today The lynx movement rules were set based on the Kramer-Schadt et al. (2004) analysis of radio collar data from lynx in the Swiss Jura. A logistic relationship was estimated for the likelihood of moving a particular distance on a particular day and this is summarised in Eqs. 1 and 2. These movements featured periods of low movement, resting, hunting, and less frequent longer movements.

$$
P_{(s)}=\Phi\left(1-\left(\frac{s^{-1}}{s_{\max }-1}\right)\right)^{x}
$$

$\mathrm{P}_{(\mathrm{s})} \quad$ Daily probability of travelling a particular distance $\mathrm{s}$

$\mathrm{s} \quad$ the distance travelled

$\mathrm{S}_{\max }$ the maximum possible distance travelled per day $45 \mathrm{~km}$

$\mathrm{x} \quad$ power function 11

[1] Source Kramer-Schadt et al. 2004 P715

Table 3 Input datasets used in the model

\begin{tabular}{llc}
\hline $\begin{array}{l}\text { Patch } \\
\text { grid }\end{array}$ & $\begin{array}{c}1 \mathrm{~km} \times 1 \mathrm{~km} \text { Raster grid Scotland and English borders including Kielder Forest. } \\
\text { Processing described in Section } 3.2\end{array}$ & $\begin{array}{c}\text { A S C I I } \\
\text { format }\end{array}$ \\
\hline $\begin{array}{c}\text { Roads } \\
\text { data }\end{array}$ & $\begin{array}{c}\text { Motorway and A road rasterized from Ordnance survey Meridian data. } \\
\text { (https:/digimap.edina.ac.uk/webhelp/os/data_information/os_ } \\
\text { products/meridian_2.htm) }\end{array}$ & $\begin{array}{c}\text { ASCII } \\
\text { format }\end{array}$ \\
\hline
\end{tabular}


$\Phi$ normalisation factor between 0 and 1

$$
\Phi=\frac{1}{\sum_{s=1}^{S_{\max }}\left(1-\left(\frac{s^{-1}}{s_{\max }-1}\right)\right)^{x}}
$$

[2] Source Kramer-Schadt et al. 2004. P715

Set initial direction of travel for today.

Movement direction is partially determined by the habitat. Each lynx agent is initially assigned a random direction of movement each day.

Lynx Sense Current Patch Type Lynx are aware of their current patch type. Their movement depends partially on the patch they are currently on. Lynx first sense their eight neighbouring patches. Any red (barrier patches) are excluded from the set of cells the lynx will consider moving to.

Move from Green If a lynx is on a green patch (dispersal habitat) and all the patches it could move to are green, the lynx calls the next part of the CHDW process which tests whether the lynx should continue in the same direction as last step? by comparing a random number against the parameter continue_straight. The value used is 0.53 the same as used in Kramer-Schadt et al. (2004).

If a lynx is on a green patch and has the option to move to a yellow patch the decision is made using the same equation as Kramer-Schadt et al. (2004):

$$
P_{\text {leave }}=n_{\text {mat }} \times P_{\text {step_into } \_ \text {matrix }}
$$

If a lynx decides to step into matrix, it then determines whether it wishes to continue in the same direction. This order of decisions is the same as in Kramer-Schadt et al. (2004).

Move from Yellow If a lynx is on a yellow patch, the lynx's value for $n$ mat is compared to Max-number-mat. If equal, it returns to its last known green patch. A lynx has a maximum distance it is willing to venture from its last known dispersal (green) patch.

\section{Road Cross Mortality}

If during any movement step a lynx finds itself on a patch which contains a major road or motorway, the road cross mortality procedure is called. The probability of mortality in this case is 0.002 . An assumption is made that the mortality probability occurs from venturing into a $1 \mathrm{~km} \times 1 \mathrm{~km}$ cell with a major road as Kramer-Schadt et al. (2004) used a spatial grain of $1 \mathrm{~km}$. A further assumption is that the roads included in the present $\mathrm{ABM}$ are comparable in terms of traffic volume, noise and other factors which may influence lynx crossing behaviour and mortality. 


\section{Summary of Differences between the Model Presented and Kramer-Schadt et al. (2004)}

The model presented provides a case study of a previously devised model (KramerSchadt et al. 2004) applied to Scotland and Kielder Forest. Table 4 summarises the differences. Where further details are given in the text, the section number is provided.

\section{Results}

\section{Results of the Model Described in Section 3}

The ABM was used to suggest a candidate release site based on dispersal patches visited. A release was simulated for every dispersal patch. The parameters used were as described in Table 2. The best release site in terms of number of dispersal patches explored per lynx is 60 and is found in Dumfries and Galloway. Figure 2 shows the mean number of patches visited by the release population in each iteration. As explained above, the mean dispersal patch visits per lynx should be at least 37 to increase the potential for lynx to establish viable territories. $30 \%$ of release points exceeded this threshold. Even at the 99.9th percentile (mean patch visits per lynx per iteration $\geq 58$ ) there are release sites in Dumfries and Galloway and Kielder Forest. The model output should be interpreted as identifying a short list of sites that are likely to facilitate effective dispersal.

As explained in Section 3.8.4 the model was calibrated by testing the extent to which simulations reproduced two patterns. The mean maximum dispersal distance was $18.5 \mathrm{~km}$. This did not meet the dispersal pattern of being within

Table 4 Summary of differences between the model described and that presented in (Kramer-Schadt et al. 2004)

\begin{tabular}{lc}
\hline Difference & $\begin{array}{c}\text { Further } \\
\text { details } \\
\text { (Section) }\end{array}$ \\
\hline Patches. The present paper has three patch types (dispersal, matrix, barrier) & 3.2 \\
Kramer-Schadt et al. (2004) has a fourth (breeding). & 3.1 \\
Purpose & 3.1 \\
The present paper examines dispersal in the first year following release. \\
Kramer-Schadt et al. (2004) examines dispersal over longer periods to assess potential for \\
movement between large areas of dispersal habitat \\
Study area
\end{tabular}




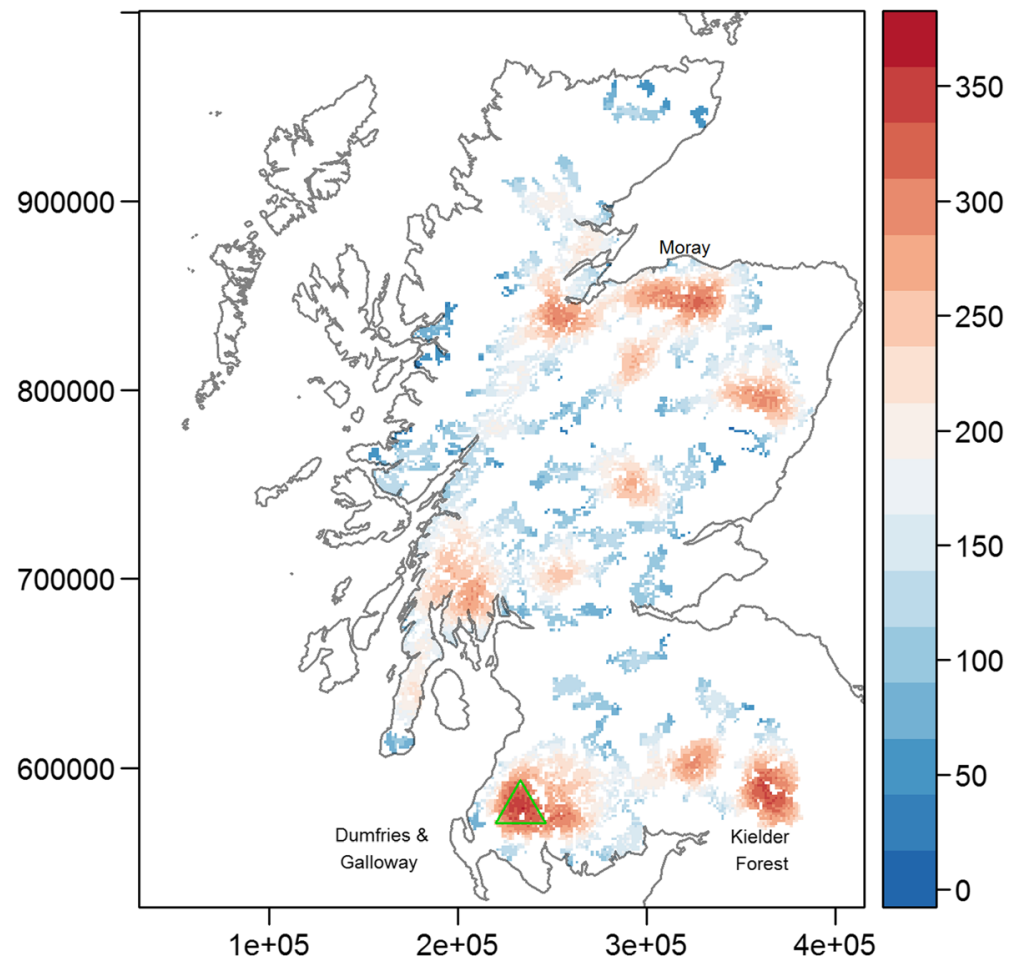

Fig. 2 The parameters used were as described in Table 2. Number of Lynxes $=6$, max_number_mat $=9$. Coordinate reference system British National Grid. The Centre of the green triangle represents the release site leading to the greatest number of dispersal patches explored. The map shading denotes Pvisits

1SD of $41.7 \mathrm{~km}$. Possible explanations for this include: the lynx release point is within a large area of dispersal habitat, the number of movement steps on which an individual will reach the edge of the area may be small. Though there are short gaps to access other large areas of dispersal habitat to the east, road crossing mortality may reduce dispersal distance. Over $81 \%$ of movement steps were on green patches (dispersal habitat) matching the second pattern. The average number of lynx surviving the first year in this simulation was 2.56 which is a survival rate of $42 \%$. When only base mortality is considered, the average number of lynx surviving is 4.68 , the survival rate is $78 \%$. The high overall mortality rate is similar to the estimates of $56-60 \%$ reported for observations in the Jura by Breitenmoser-Würsten et al. (2007).

\section{Results of Other Parameterizations}

\section{Adjusting the Number of Lynx Released}

Figure 3 shows the simulation result of 32 lynx being released. The number of dispersal patches visited per lynx is lower when 32 lynx are released (see Table 5). A possible explanation for this is that there is no explicit modelling of repulsion when lynx encounter each other. Carter et al. (2015) for example modelled tigers and considered this explicitly. It is possible that in the case of 


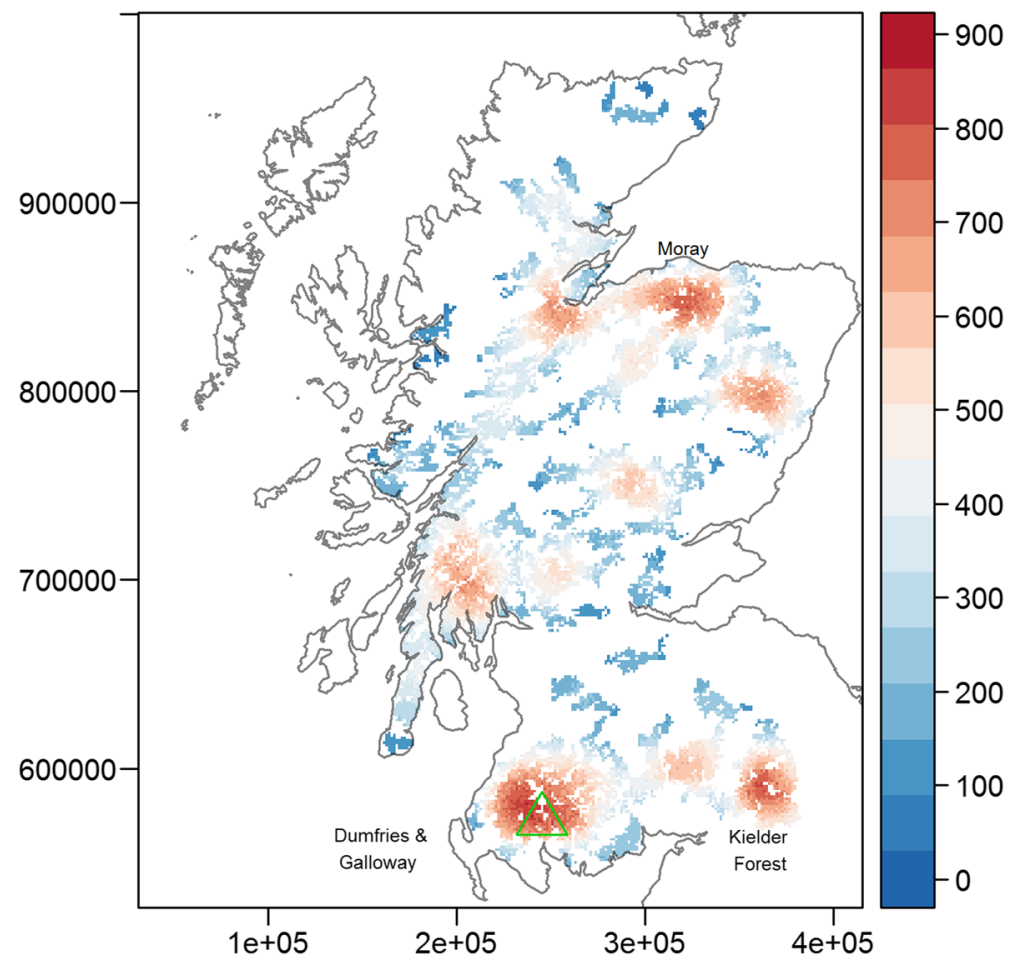

Fig. 3 Number of Lynxes $=32$, max number mat $=9$. Co-ordinate reference system British National Grid). The Centre of the green triangle represents the release site leading to the greatest number of dispersal patches explored. The map shading denotes Pvisits

lynx movement, an explicit repulsion procedure is not needed in the movement sub-model if the number of animals released is low. However if a large number of animals is released this repulsion effect may be greater. It is also possible that such a large release may simply be too large and lynx would not disperse sufficiently.

\section{Adjusting the max_number_mat Parameter}

Lynx have adaptive and varied behaviours in order to succeed over a wide range including the partially forested areas of the Jura and the Swiss Alps, contiguous forest in Bialowieza, Poland to the more sparsely forested Altai and Himalaya (Hetherington 2005). In these various environments the proportion of time local populations spend in forest and their tolerance for less wooded habitat differs (particularly where mountainous or rocky terrain provide cover). For this reason further simulations were run with an adjusted parameter. The maximum number of matrix patches a lynx was prepared to move through (max_number_mat) was increased from 9 to 60. Hetherington suggested this as a plausible distance for lynx to move between forest areas in Scotland, accounting for terrain. (Hetherington 2005). The results of simulations are shown in Figs. 4, 5 and Table 5. 
Table 5 Summary of results for simulations which considered mortality

\begin{tabular}{|c|c|c|c|c|c|c|}
\hline Simulation & $\begin{array}{l}\text { Mean number of } \\
\text { different patches } \\
\text { visited per } \\
\text { iteration }\end{array}$ & $\begin{array}{l}\text { Mean } \\
\text { patch } \\
\text { visits per } \\
\text { lynx per } \\
\text { iteration }\end{array}$ & $\begin{array}{l}\text { Mean } \\
\text { maximum } \\
\text { dispersal } \\
\text { distance }\end{array}$ & $\begin{array}{l}\text { Mean } \\
\text { lynx } \\
\text { survived } \\
\text { per } \\
\text { iteration }\end{array}$ & $\begin{array}{l}\quad \mathrm{B} \text { e } \mathrm{s} \mathrm{t} \\
\text { release } \\
\text { patch } \\
\text { British } \\
\text { National } \\
\text { Grid } \\
\text { Easting }\end{array}$ & $\begin{array}{l}\text { Best release } \\
\text { patch } \\
\text { British } \\
\text { National } \\
\text { Grid } \\
\text { Northing }\end{array}$ \\
\hline $\begin{array}{l}\text { A (with default } \\
\text { parameters) } \\
(\text { max_number_mat } \\
\quad=9, \text { lynx released }=6)\end{array}$ & 359 & 60 & 19.37 & 2.6 & (2)33 & (5)78 \\
\hline $\begin{array}{l}\text { B } \\
\text { (max_number_mat } \\
\quad=9, \text { lynx } \\
\quad \text { released }=32 \text { ) }\end{array}$ & 881 & 27.5 & 29.87 & 13.95 & (2) 45 & (5)72 \\
\hline $\begin{array}{l}\text { C } \\
\quad(\text { max_number_mat }= \\
\quad 60, \text { lynx released }=6)\end{array}$ & 398 & 66.3 & 20.41 & 2.6 & (2)33 & (5)82 \\
\hline $\begin{array}{l}\text { D } \\
(\text { max_number_mat }= \\
60, \text { lynx } \\
\text { released }=32)\end{array}$ & 893 & 27.9 & 29.42 & 13.95 & (2)43 & (5)78 \\
\hline
\end{tabular}

\section{Simulation without Mortality}

The model was also run without considering mortality. To do this the parameters Base_daily_mort and Road_cross_mort were each set to zero. The results are summarized in Table 6 below.

At the best release point identified using the parameters in Table 2, the number of dispersal patches explored per lynx would increase by $24 \%$ if there was no mortality during the first year following release. Dispersal distance would increase by $23 \%$. Even with increased dispersal distances, none of the no-mortality simulations met the dispersal calibration pattern of being within $1 \mathrm{SD}$ of $41.7 \mathrm{~km}$. All simulations in Table 6 met the calibration of having over $81 \%$ of movement steps in dispersal habitat.

\section{Applications of Models to Policy}

Based on the movement parameters used in these simulations, the physical landscape does not prevent lynx dispersing, however, the high mortality rates particularly arising from road crossings present considerable risks to re-introduced populations. There are strategies which may reduce risks e.g. partial fencing (Ascensão et al. 2013) or driver awareness campaigns. Policy in both wildlife management and transport planning may be required to reduce the mortality risk without making roads impermeable barriers for lynx. 


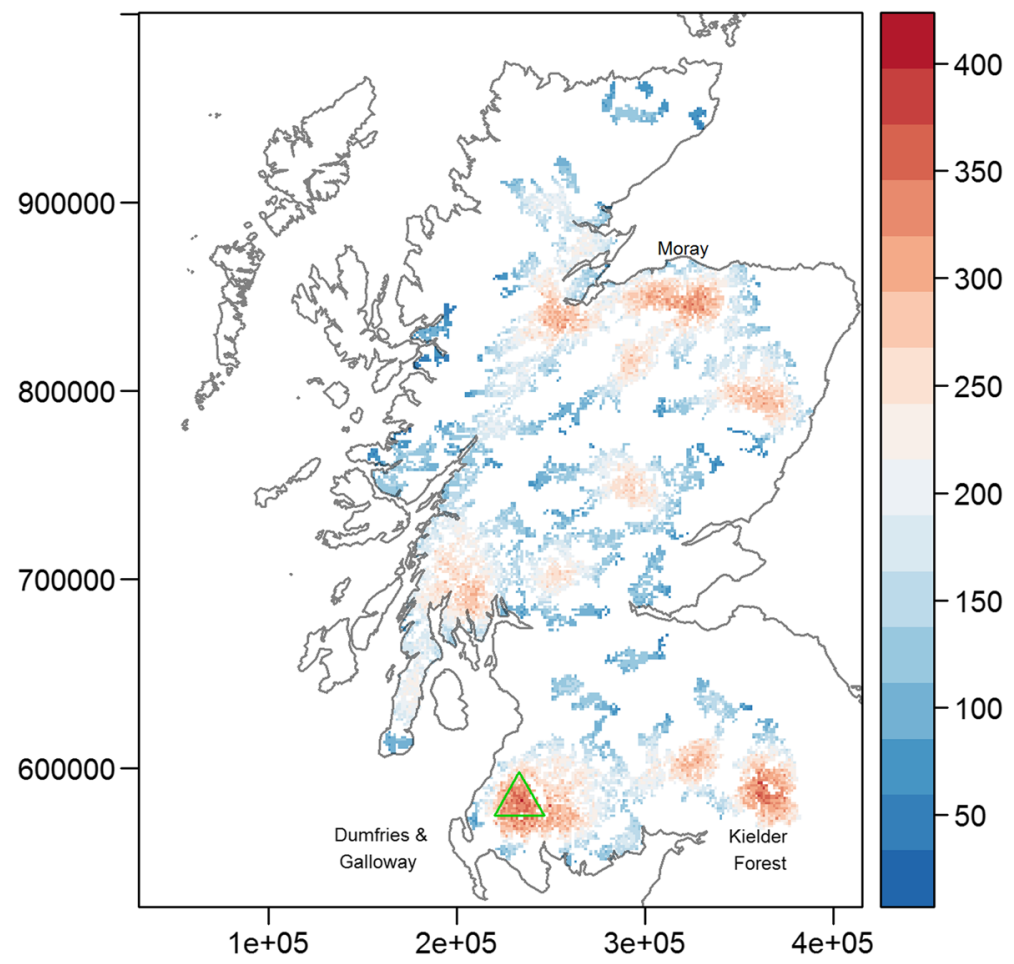

Fig. 4 Number_of_Lynxes $=6$, max_number_mat $=60$. Co-ordinate reference system British National Grid). The Centre of the green triangle represents the release site leading to the greatest number of dispersal patches explored. The map shading denotes Pvisits

In simulation runs using the parameters in Table 2 , no more than $5 \%$ of lynx movement steps were in matrix patches. The implications of this are firstly, making connections between core regions of dispersal patches is plausible but occur rarely in the short term simulations. This compliments and adds to previous static cost path analysis Hetherington (2005). Secondly, the small proportion of time and movement steps spent in matrix patches (which includes farmland) suggests a relatively low level of predation on livestock.

It is possible that stakeholders and conservationists may disagree with the parameterisations presented. ABMs allow the results of simulations to be more critically evaluated. As an example, an alternative criterion could be made that the calibration criteria should be lynx spend $18 \%$ of their time in matrix cells rather than less than $18 \%$. This was the percentage in the radio collar data from the Swiss Jura used by (Kramer-Schadt et al. 2004). The reason for simulating lynx with a different propensity to step into matrix habitat is as follows. In a different environment, to the Swiss Jura, lynx may respond by utilising non-wooded matrix habitat to a greater extent than assumed in the model. Hetherington explains this is plausible particularly where the landscape provides other types of cover. The propensity of lynx to explore matrix habitat, particularly where sheep graze, is of great concern to the farming communities where re-introductions are being considered. The effect of simulating a different lynx response to matrix habitat is summarised in Table 7 . The changed response to the environment is simulated by increasing the Pstep_into_matrix parameter. 


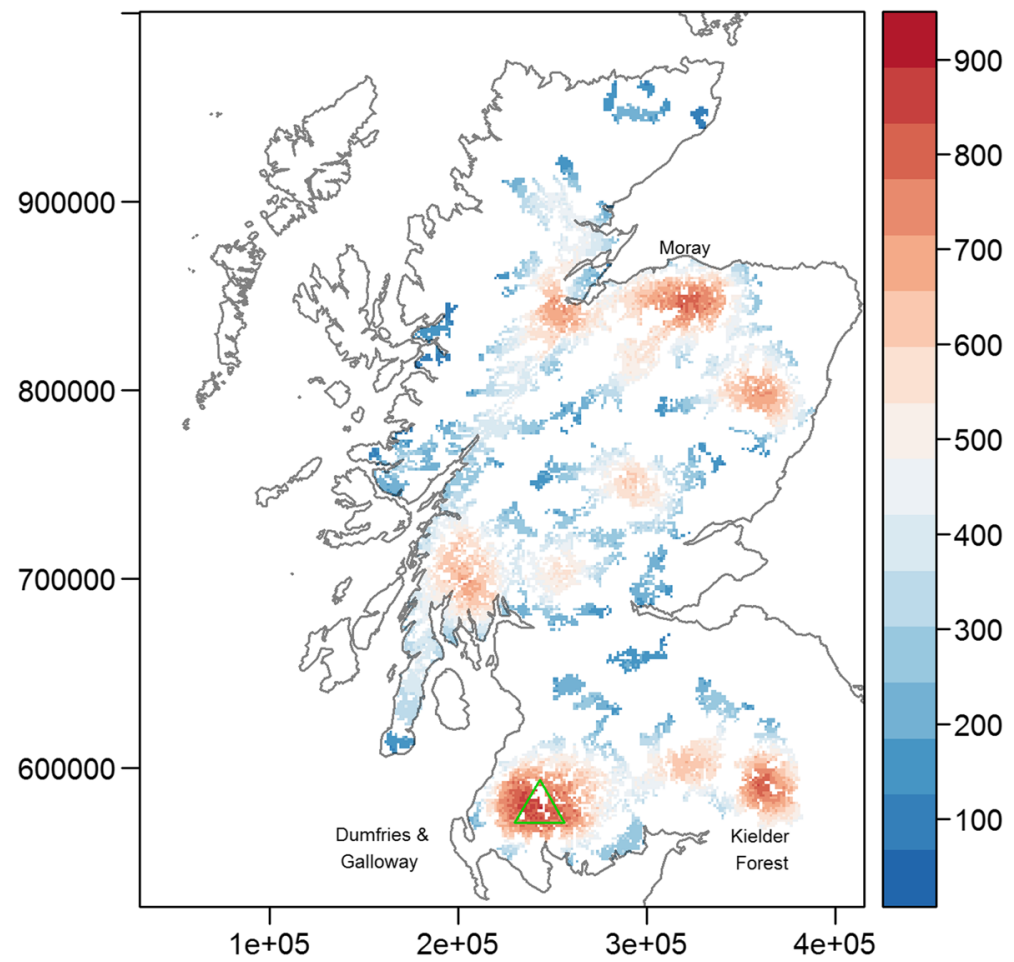

Fig. 5 Number of Lynxes $=32$, max number mat $=60$. Co-ordinate reference system British National Grid). The Centre of the green triangle represents the release site leading to the greatest number of dispersal patches explored. The map shading denotes Pvisits

This begins to show the participative and consultative potential of the ABM. Being able to quickly test different parametisations like this produces results that can be used by those familiar with observing lynx in different habitats to discuss the differences in movement that might occur in Scotland compared to Switzerland. This allows testing and development of simulations with inputs of qualitative understandings. Testing different simulations also provides information about the range of potential outcomes - allowing some estimation of the degree of uncertainty. This allows a fuller discussion with community stakeholders about where and under what circumstances conflicts could occur.

Based on research into the proposed trial re-introduction of lynx in Kielder Forest, Mansfield and Convery (2017) explain that lack of full discussion between conservationists and local farmers has generated an acrimonious situation. They note the acrimony has arisen partly because it is difficult to engage stakeholders from farming communities in a discussion of lynx preference for forest over farmland with lynx being something that is mobile and which does not have a fence around it. The spatiotemporal dynamics of lynx dispersal is not being communicated and discussed effectively - and this is causing failure to address the farmers' perceived risk of lynx predation on livestock. The ABM proposed may be developed further to assist with creating useful dialogue. Mansfield and Convery (2017) also argue that early and meaningful engagement with stakeholders is needed. This is pertinent to those who wish to consider Lynx re-introduction in Scotland. The ABM proposed in this paper 
Table 6 The effect on dispersal when mortality is not considered

\begin{tabular}{|c|c|c|c|c|c|c|c|}
\hline Simulation & $\begin{array}{l}\text { Mean } \\
\text { number of } \\
\text { different } \\
\text { patches } \\
\text { visited per } \\
\text { iteration }\end{array}$ & $\begin{array}{l}\text { Mean } \\
\text { patch } \\
\text { visits } \\
\text { per lynx } \\
\text { per } \\
\text { iteration }\end{array}$ & $\begin{array}{l}\text { Mean } \\
\text { maximum } \\
\text { dispersal } \\
\text { distance }\end{array}$ & $\begin{array}{l}\quad \mathrm{B} \text { e s t } \\
\text { release } \\
\text { patch } \\
\text { British } \\
\text { National } \\
\text { Grid } \\
\text { Easting }\end{array}$ & $\begin{array}{l}\quad \mathrm{B} \text { e s t } \\
\text { release } \\
\text { patch } \\
\text { British } \\
\text { National } \\
\text { Grid } \\
\text { Northing }\end{array}$ & $\begin{array}{l}\text { Percent } \\
\text { increase } \\
\text { in } \\
\text { patches } \\
\text { visited }\end{array}$ & $\begin{array}{l}\text { Percent } \\
\text { increase } \\
\text { in } \\
\text { dispersal } \\
\text { distance }\end{array}$ \\
\hline $\begin{array}{c}\text { E (max_number_mat }=9, \\
\text { lynx released }=6)\end{array}$ & 445 & 74 & 23.8 & (2)33 & (5)78 & 24 & 23 \\
\hline $\begin{array}{c}\text { F (max_number_mat }=9, \\
\text { lynx released }=32)\end{array}$ & 978 & 31 & 32.7 & (2)45 & $(5) 72$ & 11 & 19 \\
\hline $\begin{array}{l}\text { G } \\
\quad(\text { max_number_mat }= \\
\quad 60, \text { lynx released }=6)\end{array}$ & 450 & 75 & 24.9 & (2)33 & (5) 82 & 13 & 22 \\
\hline $\begin{array}{l}\text { H } \\
\text { (max_number_mat }= \\
60, \text { lynx } \\
\text { released }=32)\end{array}$ & 1054 & 33 & 32.7 & (2)43 & (5)78 & 18 & 11 \\
\hline
\end{tabular}

may be useful for early engagement. For example the educational and consultative benefits of dynamic visual tools such as ABM have been established (e.g. Wilensky and Rand 2015; Pettit et al. 2004).

\section{Conclusions Limitations and Further Work}

The primary aim of this paper was to build and test an Agent Based Model of dispersal for lynx re-introduction in Scotland. This made a contribution to understanding of how lynx might move in Scotland. Whilst the testing of this ABM does not offer definitive answers to re-introduction strategies it provides estimates of the potential dispersal from a particular point. The results illustrate

Table 7 Simulating changed response to matrix habitat by adjusting the Pstep_into_matrix parameter

\begin{tabular}{ll}
\hline Pstep_into_matrix & Percentage of movement steps in matrix habitat \\
\hline 0.03 & 0.045 \\
0.06 & 0.085 \\
0.09 & 0.129 \\
0.12 & 0.170 \\
0.13 & 0.190 \\
0.15 & 0.222 \\
\hline
\end{tabular}


the sensitivity to adjusting several of the parameters. The model is constructed so that lynx conservationists or stakeholders could alter the parameters to incorporate data from further lynx observation and thus calibrate it further, making it a flexible tool, which can be updated based on emerging evidence and data. For example, should the proposed trial re-introduction in Kielder proceed, this ABM would be well suited to running simulations using the highly relevant empirical observation data that it would create.

The dispersal model has some value as a conservation planning tool. The model output is visual and dynamic and can be used to illustrate "what-if scenarios" to show where lynx are likely to go. It also has the ability to represent the dynamics of mobile dispersing animals which has been identified as a barrier to engaging with stakeholders. The ability to run multiple scenarios is an important aspect of participatory ABM. (Ramanath and Gilbert 2004). If further sub-models were to be built, it would be useful to engage stakeholders in the model construction.

The model presented has limitations. The observation data is from a landscape which has some significant differences. This model does not consider in fine detail all influences on dispersal, for example, seasonal change and territory acquisition factors may be built into the model. Population density affects dispersal though the movement rules do not explicitly consider a repulsion effect between lynx that meet. Extending the model to include territory acquisition and other interactions between individual lynx could provide further insights. Roads were treated simply in this paper - noise, light and vehicle movement may scare off lynx to a degree and this could be modelled in more detail.

The ABM could be expanded to incorporate other elements of the lynx's lifecycle including reproduction and habitat change over time resulting in a full spatially explicit population model. Not only this, further developments to model human interactions such as risks from different levels of road traffic and disturbance from recreation could be included. Modelling the likelihood of sheep predation would also be insightful. There are also opportunities if expanding the model to consider the computational efficiency of algorithms and code used.

The input data may be changed as further relevant observation data becomes available. The literature shows the actual movements of lynx vary in different areas and in different studies. This means there are different plausible parameter settings for the model particularly the max-number-mat. The analysis of simulations also suggests that the outputs give insights not seen with grid based cost path models. As the success of lynx re-introduction may rely on human attitudes to and interaction with the lynx it may be useful to integrate the lynx model with a model of human use of lynx habitat areas incorporating for example livestock grazing, transport and human recreational activity. This could give an indication of potential interaction between people and lynx.

Acknowledgements I would like to acknowledge David Hetherington for kindly providing habitat data which helped define the patches used in the model, Stephanie Kramer-Schadt who helpfully answered my questions about her model of lynx re-introduction in Germany and Andy Evans who provided feedback on early versions of this work. 


\section{Compliance with Ethical Standards}

Conflict of Interest The author declares that they have no conflict of interest.

Open Access This article is distributed under the terms of the Creative Commons Attribution 4.0 International License (http://creativecommons.org/licenses/by/4.0/), which permits unrestricted use, distribution, and reproduction in any medium, provided you give appropriate credit to the original author(s) and the source, provide a link to the Creative Commons license, and indicate if changes were made.

\section{References}

Arts, K., Fischer, K., \& van der Wal, R. (2012). Common stories of reintroduction: A discourse analysis of documents supporting animal reintroductions to Scotland. Land Use Policy, 29(4), 911-920. https://doi. org/10.1016/j.landusepol.2012.01.009.

Ascensão, F., Clevenger, E., Santos-Reis, M., Urbano, P., \& Jackson, N. (2013). Wildlife-vehicle collision mitigation: Is partial fencing the answer? An agent-based model approach. Ecological Modelling, 257(Supplement C), 36-43. https://doi.org/10.1016/j.ecolmodel.2013.02.026.

Bonabeau, E. (2002). Agent-based modeling: Methods and techniques for simulating human systems. Proceedings of the National Academy of Sciences, 99(Supplement 3), 7280-7287. https://doi. org/10.1073/pnas.082080899.

Bossenbroek, J. M., Kraft, C., \& Nekola, J. (2001). Prediction of long-distance dispersal using gravity models: Zebra mussel invasion of Inland Lakes. Ecological Applications, 11(6), 1778-1788. https://doi.org/ 10.1890/1051-0761(2001)011[1778:POLDDU]2.0.CO;2.

Bousquet, F., \& Le Page, C. (2004). Multi-agent simulations and ecosystem management: A review. Ecological Modelling, 176(3-4), 313-332. https://doi.org/10.1016/j.ecolmodel.2004.01.011.

Breitenmoser U., Breitenmoser C., Okarma H, and Müller U. (2000). Status and Conservation of the Eurasian Lynx (Lynx lynx) in Europe in 2001. Strasbourg: Council of Europe. https://www.researchgate. net/publication/228776242_Action_Plan_for_the_Conservation_of_the_Eurasian_Lynx_in_Europe_ Lynx_lynx. Accessed Jan 2019.

Breitenmoser-Würsten, C., Vandel, J. M., Zimmermann, F., \& Breitenmoser, U. (2007). Demography of Lynx Lynx Lynx in the Jura Mountains. Wildlife Biology, 13(4), 381-392. https://doi.org/10.2981/09096396(2007)13[381:DOLLLI]2.0.CO;2.

Brown, C., Mcmorran, R., \& Price, R. (2011). Rewilding - A new paradigm for nature conservation in Scotland? Scottish Geographical Journal, 127(4), 288-314. https://doi.org/10.1080 /14702541.2012.666261.

Carter, N., Levin, S., Barlow, A., \& Grimm, V. (2015). Modeling Tiger population and territory dynamics using an agent-based approach. Ecological Modelling, 312(September), 347-362. https://doi.org/10.1016 /j.ecolmodel.2015.06.008.

Carver, S., Comber, A., McMorran, R., \& Nutter, S. (2012). A GIS model for mapping spatial patterns and distribution of wild land in Scotland. Landscape and Urban Planning, 104(3), 395-409. https://doi. org/10.1016/j.landurbplan.2011.11.016.

DEFRA (2018). Lynx reintroduction in Kielder Forest. GOV.UK. 2018. https://www.gov. uk/government/publications/lynx-reintroduction-in-kielder-forest. Accessed Jan 2019.

Dennis, R. (1995). Scotland's native Forest - Return of the wild. ECOS, 16(2), 17-21.

Devineau, O., Shenk, T., White, G., Doherty, P., Jr., Lukacs, P., \& Kahn, R. (2010). Evaluating the Canada Lynx reintroduction Programme in Colorado: Patterns in mortality. Journal of Applied Ecology, 47(3), 524-531. https://doi.org/10.1111/j.1365-2664.2010.01805.x.

Dunning, J. B., Jr., Stewart, D., Danielson, B., Noon, B., Root, T., Lamberson, R., \& Stevens, E. (1995). Spatially explicit population models: Current forms and future uses. Ecological Applications, 5(1), 3-11.

Grimm, V., \& Railsback, S. (2005). Individual-based modelling and ecology. Oxford: Princeton University Press http://books.google.com/books?id=12MvUbMeog8C\&printsec =frontcover \&dq= Grimm+and+Railsback+2005\#v=onepage\&q\&f=false. Accessed Jan 2019.

Grimm, V., Berger, U., Bastiansen, F., Eliassen, S., Ginot, V., Giske, J., Goss-Custard, J., et al. (2006). A standard protocol for describing individual-based and agent-based models. Ecological Modelling, 198(1), 115-126. https://doi.org/10.1016/j.ecolmodel.2006.04.023. 
Grimm, V., Berger, U., DeAngelis, D., Polhill, J., Giske, J., \& Railsback, S. (2010). The ODD protocol: A review and first update. Ecological Modelling, 221(23), 2760-2768. https://doi.org/10.1016/j. ecolmodel.2010.08.019.

Gunson, K., Mountrakis, G., \& Quackenbush, L. (2011). Spatial wildlife-vehicle collision models: A review of current work and its application to transportation mitigation projects. Journal of Environmental Management, 92(4), 1074-1082. https://doi.org/10.1016/j.jenvman.2010.11.027.

Hare, M., Letcher, R., \& Jakeman, R. (2003). Participatory modelling in natural resource management: A comparison of four case studies. Integrated Assessment, 4(2), 62-72. https://doi.org/10.1076 /iaij.4.2.62.16706.

Hetherington, D. (2005). The feasibility of reintroducing the Eurasian Lynx, Lynx Lynx to Scotland. Ph.D., University of Aberdeen. http://ethos.bl.uk/OrderDetails.do?uin=uk.bl.ethos.424959. Accessed Jan 2019.

Hetherington, D. (2006). The Lynx in Britain's past, present and future. ECOS, 27(1), 66-74.

Holt, C., Nevin, O., Smith, D., \& Convery, I. (2018). Environmental niche overlap between snow leopard and four prey species in Kazakhstan. Ecological Informatics, 48(November), 97-103. https://doi.org/10.1016 /j.ecoinf.2018.09.005.

Kramer-Schadt, S., Revilla, E., Wiegand, T., \& Breitenmoser, U. (2004). Fragmented landscapes, road mortality and patch connectivity: Modelling influences on the dispersal of Eurasian Lynx. Journal of Applied Ecology, 41(4), 711-723. https://doi.org/10.1111/j.0021-8901.2004.00933.x.

Kramer-Schadt, S., Revilla, E., \& Wiegand, T. (2005). Lynx reintroductions in fragmented landscapes of Germany: Projects with a future or misunderstood wildlife conservation? Biological Conservation, 125(2), 169-182. https://doi.org/10.1016/j.biocon.2005.02.015.

Lima, S. L., \& Zollner, P. (1996). Towards a behavioral ecology of ecological landscapes. Trends in Ecology \& Evolution, 11(3), 131-135. https://doi.org/10.1016/0169-5347(96)81094-9.

Lynx UK Trust, Clifford Chance, and University of Cumbria (2017). Application to Natural England for the Trial Reintroduction of Lynx to England. http://www.lynxuk.org/publications/EngLynxConsult.pdf. Accessed Jan 2019.

Mansfield, L, and Convery I. (2017). Re-Introducing the Eurasian Lynx, Wilding and Compensation. In . London.

McLane, A. J., Semeniuk, C., McDermid, G., \& Marceau, D. (2011). The role of agent-based models in wildlife ecology and management. Ecological Modelling, 222(8), 1544-1556. https://doi.org/10.1016/j. ecolmodel.2011.01.020.

Mills, L. S., Soulé, M., \& Doak, D. (1993). The keystone-species concept in ecology and conservation. BioScience, 43(4), 219-224. https://doi.org/10.2307/1312122.

Milner, J, and Irvine R. (2015). The Potential for Reintroduction of Eurasian Lynx to Great Britain: A Summary of the Evidence. Fordingbridge, Hampshire, UK: The British Deer Society. http://www.bds.org. uk/index.php/documents/research/67-lynxs-reintroduction-to-uk/file.

Newman, G., M. Clyde C., McGreavy B, Haklay M, Ballard H, Gray S, et al. (n.d.) Leveraging the power of place in citizen science for effective conservation decision making. Biological Conservation. Accessed August 28, 2016. https://doi.org/10.1016/j.biocon.2016.07.019.

O’Sullivan, D. (2008). Geographical information science: agent-based models. Progress in Human Geography, 32(4), 541-550. https://doi.org/10.1177/0309132507086879.

Pettit, C., Nelson A, and Cartwright W. (2004). "Using On-Line Geographical Visualisation Tools to Improve Land Use Decision-Making with a Bottom-Up Community Participatory Approach”. In Recent Advances in Design and Decision Support Systems in Architecture and Urban Planning, edited by Jos P. Van Leeuwen and Harry J. P. Timmermans, 53-68. Springer Netherlands. https://doi.org/10.1007/1-40202409-6_4.

Prell, C., Hubacek, K., Reed, M., Quinn, C., Jin, N., Holden, J., Burt, T., Kirby, M., \& Sendzimir, J. (2007). If you have a hammer everything looks like a nail: Traditional versus participatory model building. Interdisciplinary Science Reviews, 32(3), 263-282. https://doi.org/10.1179/030801807X211720.

Railsback, S. F., \& Grimm, V. (2011). Agent-based and individual-based modeling: A practical introduction. Princeton: Princeton University Press.

Ramanath, A., \& Gilbert, N. (2004). "The Design of Participatory Agent-Based Social Simulations." Text.Article. October, 31, 2004 http://jasss.soc.surrey.ac.uk/7/4/1.html. Accessed Jan 2019.

Soule, M. E. (Ed.). (1987). Viable populations for conservation. Cambridge: Cambridge University Press http://ebooks.cambridge.org/ref/id/CBO9780511623400. Accessed Jan 2019.

Tang, W., \& Bennett, D. (2010). Agent-based modeling of animal movement: A review. Geography Compass, 4(7), 682-700. https://doi.org/10.1111/j.1749-8198.2010.00337.x.

Watkins, A., J. Noble, Foster R. J., Harmsen B. J., and Doncaster C. P. (2015). A spatially explicit agent-based model of the interactions between Jaguar populations and their habitats". Ecological modelling, special 
issue: ecological modelling for ecosystem sustainability: Selected papers presented at the 19th ISEM Conference, 28-31 October 2013, Toulouse, France, 306 (June): 2e68-77. https://doi.org/10.1016/j. ecolmodel.2014.10.038.

Wilensky, U., \& Rand, W. (2015). An introduction to agent-based modeling: Modeling natural, social, and engineered complex systems with NetLogo. Cambridge, Massachusetts: The MIT Press.

Wilensky, U., \& Reisman, K. (2006). Thinking like a wolf, a sheep, or a firefly: Learning biology through constructing and testing computational theories-An embodied modeling approach. Cognition and Instruction, 24(2), 171-209. https://doi.org/10.1207/s1532690xci2402_1.

Wooldridge, M. J. (2009). An Introduction to Multiagent Systems. 2nd ed. Chichester, U.K. John Wiley \& Sons. Wyver, J. (2014). The Lynx effect: Investigating public attitudes towards the reintroduction of Eurasian Lynx Lynx Lynx to the United Kingdom. Msc, London: Imperial College London. https://www.google.co. $\mathrm{uk} / \mathrm{url}$ ? s a =t\&rct=j\& $\mathrm{q}=\&$ es $\mathrm{rc}=\mathrm{s} \& \mathrm{~s}$ ource $=\mathrm{w}$ eb $\& \mathrm{~cd}=2 \& \mathrm{cad}=\mathrm{rja} \& \mathrm{u} \mathrm{act}=8 \& \mathrm{ved}=0$ ahUKEwiSvITmheTOAhULAsAKHUUYCRkQFggmMAE\&url=http\%3A\%2F\%2Fwww.iccs.org. uk\%2Fwp-content $\% 2$ Fuploads\%2F2011\%2F10\%2FWyver_Jamie_ConSci_2014.pdf\&usg= AFQjCNGjvXPcx\%2D\%2Dj57D1JFgEz_dI9kDSpQ\&sig2=EYLrE520t7N̄nNWoHL̄1yy-Q. Accessed Jan 2019.

Zimmermann, F., \& Breitenmoser, U. (2007). Potential distribution and population size of the Eurasian Lynx Lynx Lynx in the Jura Mountains and possible corridors to adjacent ranges. Wildlife Biology, 13(4), 406416. https://doi.org/10.2981/0909-6396(2007)13[406:PDAPSO]2.0.CO;2.

Zimmermann, F., Breitenmoser-Würsten, C., \& Breitenmoser, U. (2005). Natal dispersal of Eurasian Lynx (Lynx Lynx) in Switzerland. Journal of Zoology, 267(4), 381-395. https://doi.org/10.1017 /S0952836905007545.

Publisher's Note Springer Nature remains neutral with regard to jurisdictional claims in published maps and institutional affiliations. 